\title{
Effect of iron supplementation on fatigue in nonanemic menstruating women with low ferritin: a randomized controlled trial
}

\author{
Paul Vaucher DiO MSc, Pierre-Louis Druais MD, Sophie Waldvogel MD, Bernard Favrat MD
}

\begin{abstract}
Background: The true benefit of iron supplementation for nonanemic menstruating women with fatigue is unknown. We studied the effect of oral iron therapy on fatigue and quality of life, as well as on hemoglobin, ferritin and soluble transferrin receptor levels, in nonanemic iron-deficient women with unexplained fatigue.
\end{abstract}

Methods: We performed a multicentre, parallel, randomized controlled, closed-label, observer-blinded trial. We recruited from the practices of 44 primary care physicians in France from March to July 2006. We randomly assigned 198 women aged $18-53$ years who complained of fatigue and who had a ferritin level of less than $50 \mathrm{ug} / \mathrm{L}$ and hemoglobin greater than $12.0 \mathrm{~g} / \mathrm{dL}$ to receive either oral ferrous sulfate (80 $\mathrm{mg}$ of elemental iron daily; $n=102)$ or placebo $(n=96)$ for 12 weeks. The primary outcome was fatigue as measured on the Current and Past Psycho-

$\mathrm{T}$ he prevalence of fatigue ranges from $14 \%$ to $27 \%$ among patients in primary care. ${ }^{1}$ In addition, $1 \%-2 \%$ of visits to general practices are because of fatigue, and women are three times more likely than men to mention fatigue. ${ }^{1}$ Unexplained fatigue can be caused by iron deficiency. ${ }^{2}$ Verdon and coauthors found an improvement in fatigue following iron supplementation in nonanemic women with unexplained fatigue. ${ }^{3}$ However, the hemoglobin levels of these patients were not available, which may have contributed to the ongoing debate about the appropriateness of reference limits defining anemia in women. ${ }^{4,5}$ Thus, the effectiveness of iron supplementation in nonanemic menstruating women with major fatigue without an obvious clinical cause is unknown. ${ }^{6}$ Our main objective was to test the hypothesis that oral iron therapy for a short period may improve fatigue, hemoglobin, iron stores and quality of life in menstruating nonanemic women whose ferritin logical Scale. Biological markers were measured at 6 and 12 weeks.

Results: The mean score on the Current and Past Psychological Scale for fatigue decreased by $47.7 \%$ in the iron group and by $28.8 \%$ in the placebo group (difference $-18.9 \%, 95 \% \mathrm{Cl}$ -34.5 to $-3.2 ; p=0.02$ ), but there were no significant effects on quality of life $(p=0.2)$, depression $(p=0.97)$ or anxiety $(p=0.5)$. Compared with placebo, iron supplementation increased hemoglobin $(0.32 \mathrm{~g} / \mathrm{dL} ; p=0.002)$ and ferritin $(11.4 \mu \mathrm{g} / \mathrm{L} ; p<0.001)$ and decreased soluble transferrin receptor $(-0.54 \mathrm{mg} / \mathrm{L} ; p<0.001)$ at 12 weeks.

Interpretation: Iron supplementation should be considered for women with unexplained fatigue who have ferritin levels below $50 \mu \mathrm{g} / \mathrm{L}$. We suggest assessing the efficiency using blood markers after six weeks of treatment. Trial registration no. EudraCT 2006-000478-56.

levels are below $50 \mu \mathrm{g} / \mathrm{L}$. Our secondary objective was to evaluate whether this effect is dependent on the initial levels of hemoglobin, ferritin or transferrin saturation.

\section{Methods}

\section{Design}

We performed a 12-week multicentre, doubleblind, placebo-controlled, parallel group, pragmatic $^{7,8}$ randomized trial with a 1:1 allocation ratio.

\section{Setting and participants}

We asked general practitioners from 44 private practices in France to invite women who presented with fatigue to participate in this study. To be eligible, the following criteria had to be met: (a) be menstruating women, (b) be between 18 and 50 years old, (c) report considerable fatigue ( $>6$ on a 1-10 Likert scale) without obvious clinical causes, (d) not have anemia
Competing interests: Bernard Favrat, Paul Vaucher and Sophie Waldvogel have received funding from Robapharm and Pierre Fabre for a study of the effects of iron supplementation in blood donors. Bernard Favrat is a member of an iron deficiency meeting board sponsored by Vifor Pharma. He has given lectures to and provided expert testimony for Pierre Fabre

Médicament and Vifor

Pharma. He holds grant funding from Pierre Fabre

Médicament and Vifor

Pharma. Pierre-Louis

Druais has received consulting fees from Pierre

Fabre Médicament.

This article has been peer reviewed.

Correspondence to: Bernard Favrat, Bernard.Favrat@hospvd.ch

CMAJ 2012. DOI:10.1503 /cmaj.110950 
(hemoglobin $\geq 12.0 \mathrm{~g} / \mathrm{dL}$ ), (e) have a low or borderline ferritin level $(<50 \mu \mathrm{g} / \mathrm{L})$, (f) not have a known pathology that could explain the fatigue (e.g., psychiatric, thyroid, liver, rheumatic, renal, cardiovascular, pulmonary or oncologic cause), (g) not be pregnant or breastfeeding, (h) not have a digestive disorder that could alter the absorption of the study treatment and (i) not already be taking iron supplementation. Patients were only included after all inclusion criteria were met, some of which were verified by testing a blood sample at a centralized laboratory seven days before allocation.

The study was registered on Feb. 20, 2006, with EudraCT (no. 2006-000478-56) and was approved by an independent ethics committee (Comité Consultatif pour la Protection des Personnes se prêtant à des Recherches Biomédicales, Saint-Germain-en-Laye) before its initiation (protocol no. L00008CP301). All patients signed an informed consent form before inclusion.

\section{Randomization and interventions}

The clinical pharmacy department of the sponsor (Pierre Fabre) generated a simple random allocation sequence without restriction. This list was computer generated by use of an internal software program at Pierre Fabre, which was created in accordance with their Information Technology Service and Quality Assurance Department. This sequence randomly designated 360 consecutive entries to receive either iron or placebo in a 1:1 ratio. Each drug package was coded with a unique number according to the randomization schedule and was sent to the relevant practice. General practitioners enrolled the patients and gave them sequentially numbered containers. The allocation remained concealed to patients, general practitioners, caregivers and principle investigators until the end of the trial. During the analyses, the statistician remained blinded as to what treatment each group received. The clinical pharmacy service was the sole possessor of the randomization list during the study period until the database was locked. The coding of groups was determined by the pharmacy after the analyses were complete.

Participants were instructed to take orally either $80 \mathrm{mg} / \mathrm{d}$ prolonged-release ferrous sulfate (Tardyferon; Pierre Fabre Médicament, Boulogne, France) or placebo before or after meals for 12 weeks. The length of the treatment period was justified on a physiologic basis because more than one month is needed to enlarge the erythropoietic marrow and obtain a change in red blood cell indices, particularly among nonanemic people. The iron and placebo treatments were identical in appearance and taste, and the dose regimens were the same.

\section{Outcomes and follow-up}

The primary outcome was the level of fatigue perceived by patients. We assessed fatigue at baseline and after 12 weeks by use of the Current and Past Psychological Scale (le questionnaire de la fatigue de Pichot et Brun) fatigue score, which ranges from 0 to 40 points. ${ }^{9}$ This questionnaire is a validated 24-item self-administered questionnaire with three subscales (fatigue, anxiety and depression), each with eight items. We also examined levels of depression and anxiety as additional outcomes. Each item was scored on a five-point Likert scale. Secondary outcomes were other measurements of fatigue, assessed by use of the Multidimensional Assessment of Fatigue score,,$^{10}$ which ranges from 0 to 50 points, and the vitality item from the short-form of the Self-Reported Health Questionnaire (SF-12), ${ }^{11}$ which ranges from 0 to 5 points. We also assessed the effects on quality of life using the entire SF-12 scale and the entire Current and Past Psychological Scale.

Blood samples for each patient were sent from a local laboratory to a central laboratory seven days before inclusion and at 6 and 12 weeks. Thyroid stimulating hormone, C-reactive protein, hemoglobin, ferritin, red blood cell count, mean corpuscular volume, hematocrit, soluble transferrin receptor and transferrin saturation were measured.

Patients were asked about any adverse reactions and about any physical, psychological and hemorrhagic events. Adherence to treatment was measured by counting pills.

\section{Statistical analysis}

We calculated sample size for the Current and Past Psychological Scale fatigue score. Using clinical recommendations, the study was to detect a minimum treatment effect of one point between treatment group and placebo. ${ }^{12}$ Using effect size from a previous study, ${ }^{3}$ we therefore powered our study to significantly detect a decrease by 1.8 points in the treatment group versus 0.8 in the placebo group (SD 2.0). With a power set at 0.9 and a significance level set at $0.05,85$ patients were required in each group. We increased the sample size by $30 \%$ to compensate for drop-outs and incomplete questionnaires; therefore, the total number to be randomized was 240.

We used intention-to-treat analysis for all analyses. No interim analysis or stopping rule was judged to be necessary. To account for missing data, we used a hot-deck method with 10 imputations randomly selecting data within each group. We compared changes in outcomes between baseline and 12 weeks follow-up and 
between placebo and iron (ferrous sulfate, $\mathrm{FeSO}_{4}$ ) groups using generalized estimating equations to calculate an averaged least-squares mean between groups after adjustment for baseline values and clustering effects between physicians. We also tested whether the effects were dependent on initial hemoglobin, ferritin or transferrin saturation values. Stratified analysis for ferritin was per-protocol; we amended the analysis for hemoglobin before starting the analysis but after the data were collected. The analysis for transferrin saturation was post-hoc.

\section{Results}

Patients were recruited from Apr. 1, 2006, to Aug. 31, 2006, from 44 general practices in France. In total, 243 patients were screened for eligibility. Of these, 30 were not eligible and 15 refused to be included (Figure 1). We randomly assigned 198 patients to receive either an iron supplement $(n=102)$ or placebo $(n=96)$. Randomization ensured that the groups had similar characteristics at baseline for all outcomes. However, more patients in the iron group had a hemoglobin blood concentration of less than $13.0 \mathrm{~g} / \mathrm{dL}$ and a ferritin level of less than $15 \mu \mathrm{g} / \mathrm{L}$ (Table 1).

\section{Effects on outcomes}

Intention-to-treat analysis showed that patients receiving the iron supplement had a 3.5 point improvement $(95 \%$ confidence interval [CI] 0.3 to 6.7) in their fatigue score on the Current and Past Psychological Scale compared with those in the placebo group; thus, patients who received iron reported a $47.7 \%$ decrease in fatigue,

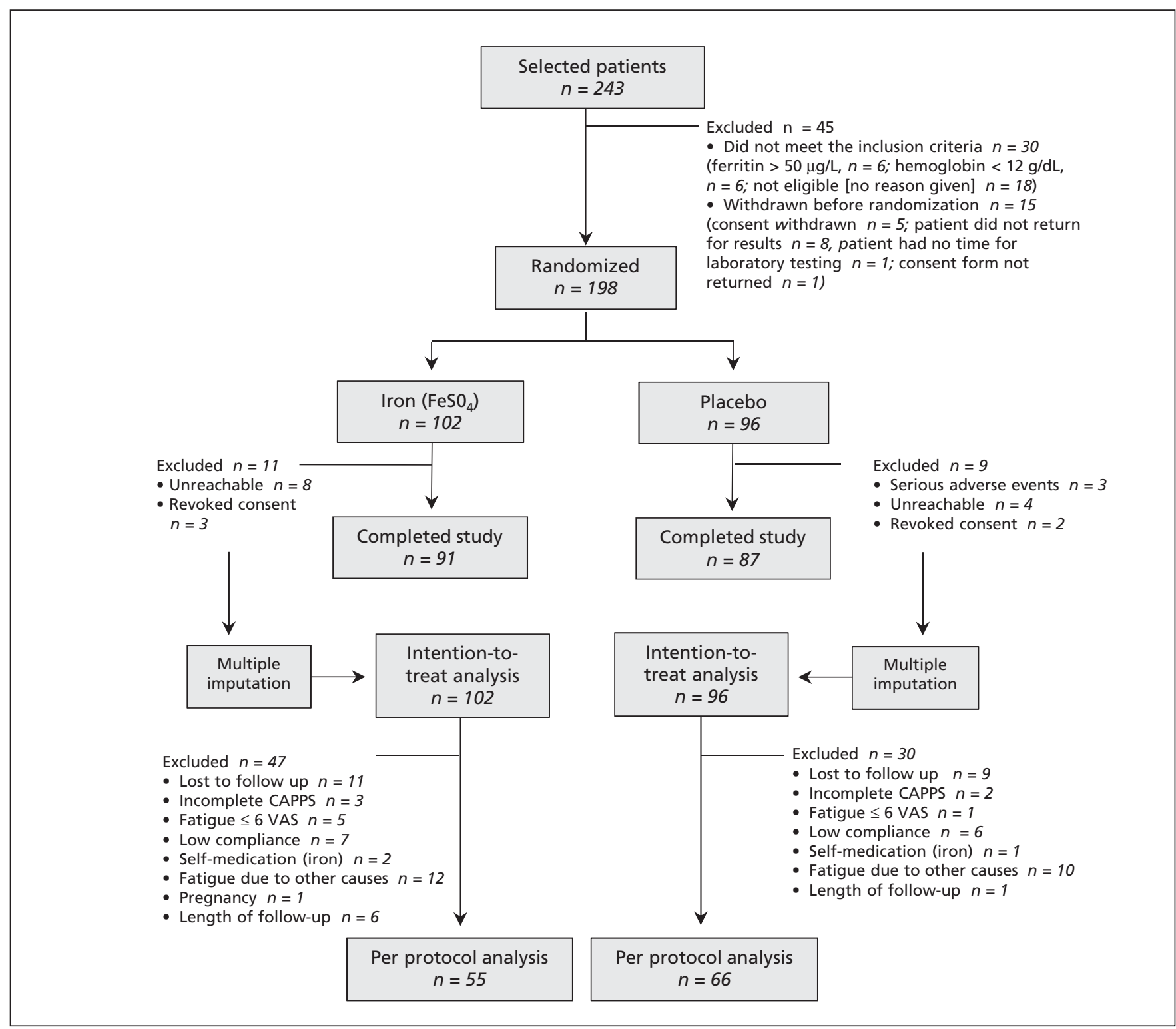

Figure 1: Flow of patients through the trial. CAPPS = Current and Past Psychological Scale, VAS = Visual Analogue Scale. 
whereas patients in the placebo group reported a decrease of $28.8 \%$. Iron also had significant effects on the global fatigue index from the Multidimensional Assessment of Fatigue Scale ( $p=$ $0.03)$ and its severity index $(p=0.03)$. Iron supplementation did not have any effect on anxiety or depression scores (Table 2). There were no significant effects on the indicators of quality of life.

After six weeks of iron treatment, there were significant effects on hemoglobin $(0.3 \mathrm{~g} / \mathrm{dL} ; p=$ $0.001)$, ferritin $(6.8 \mu \mathrm{g} / \mathrm{L} ; p<0.001)$, mean corpuscular volume (1.2 fL; $p=0.01$ ), hematocrit $(0.8 \% ; p=0.03)$, soluble transferrin receptor $(-0.4 \mathrm{mg} / \mathrm{L} ; p<0.001)$ and transferrin saturation $(6.6 \% ; p<0.001)$. The results were similar after 12 weeks of treatment (Table 2; Appendix 1, available at www.cmaj.ca/lookup/suppl/doi:10 .1503/cmaj.110950/-/DC1).

Table 1: Baseline characteristics of trial participants

\begin{tabular}{|c|c|c|c|}
\hline \multirow[b]{2}{*}{ Characteristic } & \multicolumn{2}{|c|}{ Group; no. (\%) or mean \pm SD } & \multirow[b]{2}{*}{$\begin{array}{l}\text { Relative difference } \\
\text { from placebo, } \dagger \%\end{array}$} \\
\hline & $\begin{array}{c}\text { Iron* } \\
n=102\end{array}$ & $\begin{array}{c}\text { Placebo } \\
n=96\end{array}$ & \\
\hline Age, yr & $36.4 \pm 9.3$ & $37.3 \pm 9.5$ & 2.8 \\
\hline Previous iron deficiency & $60(58.8)$ & $51(53.1)$ & -9.7 \\
\hline Previous pregnancy & $58(56.9)$ & $54(56.3)$ & -10.5 \\
\hline Menorrhagia & $46(45.1)$ & $37(38.5)$ & -14.6 \\
\hline Depression (CAPPS score) $\ddagger$ & $12.1 \pm 9.7$ & $10.0 \pm 12.5$ & 4.0 \\
\hline Anxiety (CAPPS score) $\ddagger$ & $11.4 \pm 8.7$ & $9.9 \pm 13.0$ & 13.4 \\
\hline \multicolumn{4}{|l|}{ Blood characteristics } \\
\hline Thyroid stimulating hormone, uU/ml & $1.72 \pm 1.0$ & $1.84 \pm 1.1$ & 6.8 \\
\hline C-reactive protein, mg/L & $2.86 \pm 5.5$ & $2.13 \pm 3.3$ & $-27.6 \S$ \\
\hline Hemoglobin, g/dL & $13.5 \pm 0.9$ & $13.6 \pm 0.8$ & 1.2 \\
\hline Hemoglobin $<13.0 \mathrm{~g} / \mathrm{dL}$ & $32(31.4)$ & $17(17.7)$ & $-43.6 \S$ \\
\hline Ferritin, $\mu g / L$ & $22.5 \pm 12.7$ & $23.3 \pm 11.6$ & 3.7 \\
\hline Ferritin $<15 \mathrm{ug} / \mathrm{L}$ & $33(32.4)$ & $23(24.0)$ & $-37.3 \S$ \\
\hline Red blood cells, $\times 10^{12} / \mathrm{L}$ & $4.47 \pm 0.31$ & $4.50 \pm 0.31$ & 0.9 \\
\hline Mean corpuscular volume, fL & $92.0 \pm 5.0$ & $92.6 \pm 5.3$ & 0.7 \\
\hline Hematocrit, \% & $41.0 \pm 2.7$ & $41.6 \pm 2.6$ & 1.5 \\
\hline Transferrin, g/L & $2.67 \pm 0.49$ & $2.63 \pm 0.51$ & -1.5 \\
\hline Soluble transferrin receptor, mg/L & $3.44 \pm 1.1$ & $3.60 \pm 1.1$ & 4.4 \\
\hline Transferrin saturation, $\%$ & $12.6 \pm 25.3$ & $12.5 \pm 24.6$ & 2.8 \\
\hline Transferrin saturation $\leq 20 \%$ & $38(37.3)$ & $41(42.7)$ & 14.7 \\
\hline \multicolumn{4}{|l|}{ Fatigue, $\neq$} \\
\hline CAPPS score for fatigue & $25.4 \pm 8.6$ & $25.0 \pm 8.7$ & -1.5 \\
\hline Global fatigue index, MAF & $37.4 \pm 6.2$ & $37.0 \pm 5.9$ & -0.8 \\
\hline Severity of fatigue, MAF & $7.98 \pm 0.95$ & $7.94 \pm 0.84$ & -0.4 \\
\hline Vitality score, SF-12 & $4.75 \pm 0.96$ & $4.56 \pm 1.0$ & -4.2 \\
\hline \multicolumn{4}{|l|}{ Quality of lifeł } \\
\hline CAPPS score & $48.3 \pm 22.0$ & $50.7 \pm 21.1$ & 4.7 \\
\hline SF-12 & $76.7 \pm 12.0$ & $76.2 \pm 12.6$ & -0.6 \\
\hline Mental score SF-12 & $34.3 \pm 6.6$ & $33.8 \pm 6.3$ & -1.5 \\
\hline Physical score SF-12 & $42.5 \pm 8.3$ & $42.4 \pm 7.6$ & -0.1 \\
\hline \multicolumn{4}{|c|}{$\begin{array}{l}\text { Note: CAPPS = Current and Past Psychological Scale, MAF = Multidimensional Assessment of Fatigue Scale, SD = standard } \\
\text { deviation, SF12 = short-form Self-Reported Health Questionnaire. } \\
\text { *Iron = prolonged-release ferrous sulfate. } \\
\text { tCalculated as (placebo - iron)/iron (FeSO } \\
\text { flmputed missing data: CAPPS total: } 5 \text { in iron group, } 4 \text { in placebo group; CAPPS fatigue: } 3 \text { in iron group, } 1 \text { in placebo; CAPPS } \\
\text { depression: } 4 \text { in iron group, } 2 \text { in placebo group; CAPPS anxiety: } 2 \text { in iron group, } 4 \text { in placebo group; MAF global fatigue index: } 8 \\
\text { in iron group, } 6 \text { in placebo group; MAF severity index: } 1 \text { in iron group; SF-12: } 2 \text { in iron group; SF-12 } 1{ }_{10}: 1 \text { in iron group. } \\
\text { §Considered to be a baseline imbalance. }\end{array}$} \\
\hline
\end{tabular}


Adjustment for baseline imbalances between the groups (C-reactive protein level, hemoglobin $<13.0 \mathrm{~g} / \mathrm{dL}$, ferritin $<15 \mu \mathrm{g} / \mathrm{L}$ ) did not alter the results. The effects of iron on fatigue, quality of life and hemoglobin were independent of ferritin concentrations below or above $15 \mu \mathrm{g} / \mathrm{L}$ and of transferrin saturation below or above $20 \%$ (Appendix 2, available at www.cmaj.ca/lookup /suppl/doi:10.1503/cmaj.110950/-/DC1). The effects of iron supplementation on hemoglobin values were more substantial $(1.0 \mathrm{~g} / \mathrm{dL}$ v. 0.1 $\mathrm{g} / \mathrm{dL} ; p<0.001$ ) for women whose initial hemoglobin concentration was below $13.0 \mathrm{~g} / \mathrm{dL}$. For the other biological markers (except soluble transferrin receptor concentration), there was no significant treatment benefit for patients with an initial hemoglobin value below $13 \mathrm{~g} / \mathrm{dL}$, compared with other patients (Table 3 ).

After adjustment for clustering at the physician level, per-protocol analysis that excluded patients

Table 2: Intention-to-treat analysis of the changes from baseline to 12 weeks in the iron and placebo groups

\begin{tabular}{|lcc|c|} 
& \multicolumn{2}{c}{ Mean change (adjusted)* $(\mathrm{SD})$} & $\begin{array}{c}\text { Treatment effect, } \neq \\
\text { Variable }\end{array}$ \\
\cline { 2 - 3 } & $\begin{array}{c}\text { Iront } \\
n=102\end{array}$ & $\begin{array}{c}\text { Placebo } \\
\text { mean change (adjusted), } \\
(95 \% \mathrm{Cl})\end{array}$ \\
\hline
\end{tabular}

\section{Fatigue}

Fatigue score (CAPPS; 0-40 points)

\begin{tabular}{lllrlrl} 
Effect on score & -12.2 & $(10.2)$ & -8.7 & $(11.7)$ & $-3.46(-6.7$ to -0.3$)$ \\
\hline Change over time, \% & -47.7 & $(35.6)$ & -28.8 & $(57.1)$ & $-18.9(-34.5$ to -3.2$)$
\end{tabular}

Global fatigue index (MAF; 0-50 points)

\begin{tabular}{|lllrlr} 
Effect on score & -16.2 & $(11.8)$ & -11.2 & $(10.8)$ & $-4.0(-7.6$ to -0.4$)$ \\
\hline Change over time, \% & -41.3 & $(30.5)$ & -30.8 & $(27.6)$ & $-10.5(-19.2$ to -1.9$)$
\end{tabular}

Severity index of fatigue (MAF; 0-10 points)

\begin{tabular}{lrrrrr} 
Effect on score & -3.6 & $(2.5)$ & -2.7 & $(2.3)$ & $-0.87(-1.5$ to -0.08$)$ \\
\hline Change over time, \% & -43.3 & $(30.1)$ & -33.6 & $(27.5)$ & $-9.7(-18.1$ to -1.2$)$
\end{tabular}

\section{Blood characteristics}

\begin{tabular}{|c|c|c|c|}
\hline Hemoglobin, g/dL & $0.28 \quad(0.79)$ & $-0.05 \quad(0.83)$ & 0.32 (0.11 to 0.52$)$ \\
\hline Ferritin, $\mu g / L$ & $11.6(13.7)$ & $0.2(11.0)$ & 11.4 (7.5 to 15.3 ) \\
\hline Red blood cells, $\times 10^{12} / \mathrm{L}$ & $0.01 \quad(0.19)$ & $-0.02 \quad(0.21)$ & $0.02(-0.06$ to 0.10$)$ \\
\hline Mean corpuscular volume, $\mathrm{fL}$ & $1.4 \quad(3.5)$ & $-0.6 \quad(3.2)$ & 1.9 (1.1 to 2.7$)$ \\
\hline Hematocrit, \% & $0.7 \quad(2.7)$ & $-0.4 \quad(2.5)$ & $1.0(0.2$ to 1.7$)$ \\
\hline Transferrin, g/L & $-0.17 \quad(0.49)$ & $0.02 \quad(0.38)$ & $-0.15(-0.3$ to -0.05$)$ \\
\hline $\begin{array}{l}\text { Soluble transferrin receptor, } \\
\mathrm{mg} / \mathrm{L}\end{array}$ & $-0.66 \quad(0.69)$ & $-0.13(0.51)$ & $-0.54(-0.8$ to -0.28$)$ \\
\hline Transferrin saturation, \% & $2.8(14.2)$ & $-0.9 \quad(14.1)$ & $3.8(0.1$ to 7.6$)$ \\
\hline \multicolumn{4}{|c|}{ Mental disorders (CAPPS; 0-40 points) } \\
\hline Depression & $(6.5)$ & $-4.9 \quad(7.4)$ & $0.04(-2.0$ to 2.1$)$ \\
\hline Anxiety & $(9.0)$ & (9.1) & $-2.0(-4.9$ to 0.9$)$ \\
\hline \multicolumn{4}{|l|}{ Quality of life } \\
\hline SF-12 (0-100 points) & $8.8 \quad(13.4)$ & $6.0 \quad(12.9)$ & $2.8(-1.2$ to 6.8$)$ \\
\hline $\begin{array}{l}\text { Physical score, SF-12 (0-50 } \\
\text { points) }\end{array}$ & $(8.4)$ & (6.8) & $2.3(-0.4$ to 5.0$)$ \\
\hline $\begin{array}{l}\text { Mental score, SF-12 (0-50 } \\
\text { points) }\end{array}$ & $(8.6)$ & (8.4) & $0.7(-1.2$ to 2.6$)$ \\
\hline $\begin{array}{l}\text { CAPPS total score, }(0-120 \\
\text { points) }\end{array}$ & $-21.3 \quad(20.5)$ & $-16.9 \quad(21.4)$ & $-4.4(-11.2$ to 2.4$)$ \\
\hline
\end{tabular}

Note: CAPPS = Current and Past Psychological Scale, $\mathrm{Cl}=$ confidence interval, $\mathrm{MAF}=$ multidimensional assessment of fatigue scale, SD = standard deviation, SF-12 = short form Self-Reported Health Questionnaire.

* Mean differences between baseline and 12 weeks were adjusted for clustering effects at the physician level.

tIron = prolonged-release ferrous sulfate $\left(\mathrm{FeSO}_{4}\right)$.

¥Generalized estimating equations were used to calculate the average least-squares mean between groups adjusted for baseline values and the clustering effect between physicians. A hot-deck method with 10 imputations was used to account for data that were missing and lost to follow-up. 
with protocol deviations showed similar results, with a 2.1 point greater decrease in fatigue score (95\% CI -2.6 to 6.7) in the iron group $(n=55)$ on the Current and Past Psychological Scale compared with the placebo group $(n=66)$.

\section{Adverse events}

During the study, 59/198 patients (29.8\%) reported at least one adverse event: $35 / 102$ $(34.3 \%)$ in the iron group and 24/96 (25.0\%) in the placebo group $\left(\chi^{2}=2.1, p=0.2\right)$. Twelve $(11.8 \%)$ patients in the iron group and 10 $(10.4 \%)$ in the placebo group reported gastrointestinal disorders. In total, five patients experienced a serious adverse event. In the iron group, one patient was admitted to hospital for abdominoplasty and another was pregnant; both interrupted their treatment but were followed-up at 12 weeks. In the placebo group, two patients were admitted to hospital, one for thyroid adenoma and one for gynecological surgery; both were lost to follow-up. A third patient was in a severe road accident. No deaths were reported, and none of the serious adverse events appeared to be related to the study treatment.

\section{Interpretation}

We found that iron supplementation for 12 weeks decreased fatigue by almost $50 \%$ from baseline, a significant difference of $19 \%$ compared with placebo, in menstruating iron-deficient nonanemic women with unexplained fatigue and ferritin levels below $50 \mu \mathrm{g} / \mathrm{L}$. Iron supplementation did not have a significant effect on measured indicators of quality of life apart from those directly related to fatigue. However, our results suggest that iron supplementation improves hemoglobin, ferritin, hematocrit, mean corpuscular volume and soluble transferrin as early as six weeks after starting treatment.

Our study confirms and adds to the findings of the randomized placebo-controlled clinical trial of oral iron supplementation by Verdon and colleagues. ${ }^{3}$ Their study was shorter in duration (one month) and did not limit inclusion to severe fatigue; nevertheless, the effect size was similar to that in our study, except for hemoglobin, which was not measured after treatment. In addition, Krayenbuehl and coauthors ${ }^{13}$ found significant effects on fatigue following intravenous iron therapy and reported a similar effect, although not significant, on hemoglobin. The effects of iron on hemoglobin concentration seem to be similar to those observed in postpartum nonanemic women, ${ }^{14}$ military women with iron deficiency ${ }^{15}$ and nonanemic women following blood donation. ${ }^{16}$ These changes apparently occur within six weeks of starting treatment. ${ }^{13}$

Patterson and colleagues' observational findings suggested that iron could improve quality of life. ${ }^{17}$ However, the effect size for quality of life appears to be smaller than for fatigue alone; thus, our study was underpowered to reveal a significant effect. Positive effects on physical and psychological performances can be explained by the known effects of iron, which include improving aerobic adaptation, endurance capacity, ${ }^{15,18,19}$ muscle fatigability, ${ }^{20,21}$ restless leg syndrome, ${ }^{22}$ memory, verbal learning and cognitive function. ${ }^{23-25}$

The effects of iron deficiency on fatigue can be explained by decreased activity of irondependent enzymes; for example, those affecting the metabolism of neurotransmitters that enhance neurophysiologic changes. ${ }^{26-29}$ However, we presume that such physiologic changes could be confused with depression or anxiety; thus, the effect of iron supplementation on mood disor-

\begin{tabular}{|c|c|c|c|}
\hline \multirow[b]{2}{*}{ Variable } & \multicolumn{2}{|c|}{ Treatment effect* 12 weeks - baseline $(95 \% \mathrm{Cl})$} & \multirow[b]{2}{*}{$\begin{array}{l}p \text { value, } \\
\text { interaction } \\
\text { term }\end{array}$} \\
\hline & $\begin{array}{c}\text { Initial hemoglobin } \\
\text { level }<13.0 \mathrm{~g} / \mathrm{dL} \\
n=49\end{array}$ & $\begin{array}{c}\text { Initial hemoglobin } \\
\text { level } \geq 13.0 \mathrm{~g} / \mathrm{dL} \\
n=149\end{array}$ & \\
\hline Hemoglobin, g/dL & 0.97 (0.54 to 1.40$)$ & $0.09(-0.22$ to 0.41$)$ & $<0.001$ \\
\hline Ferritin, $\mu \mathrm{g} / \mathrm{L}$ & $8.4(2.0$ to 14.8$)$ & 12.7 (7.5 to 17.9$)$ & 0.4 \\
\hline Mean corpuscular volume, $\mathrm{fL}$ & $1.0(-1.8$ to 3.9$)$ & $2.2(0.9$ to 3.5$)$ & 0.4 \\
\hline Hematocrit, \% & 2.3 (0.2 to 4.4$)$ & $0.5(-0.7$ to 1.7$)$ & 0.1 \\
\hline Transferrin, g/L & $-0.1(-0.4$ to 0.2$)$ & $-0.2(-0.4$ to 0.03$)$ & 0.5 \\
\hline Soluble transferrin receptor, $\mathrm{mg} / \mathrm{L}$ & $-0.89(-1.6$ to -0.2$)$ & $-0.4(-0.6$ to -0.1$)$ & 0.05 \\
\hline Transferrin saturation, $\%$ & $2.5(-5.7$ to 10.7$)$ & $3.8(-1.7$ to 9.2$)$ & 0.8 \\
\hline
\end{tabular}


ders remains unknown. Our results suggest that an increase in erythropoiesis could be limited to women with a hemoglobin concentration below $13.0 \mathrm{~g} / \mathrm{dL} .^{30}$ The appropriateness of the official definition of the lower limit for normal hemoglobin concentrations in women has been debated. ${ }^{31}$ The biological definition of iron-deficiency anemia is based on the reduction of erythropoiesis due to a lack of available iron. Hemoglobin cutoff values serve as a surrogate and do not truly reflect all individuals' erythropoietic function correctly. Our results confirm that some women with $12.0 \mathrm{~g} / \mathrm{dL}$ or higher hemoglobin concentrations have increased erythropoiesis following iron supplementation, suggesting that they were iron deficient. Furthermore, blood markers do not necessarily reflect iron stores in other compartments. A recent study ${ }^{16}$ suggests that following blood donation, iron supplementation can improve erythropoiesis without affecting fatigue or muscular function. Therefore, fatigue might only occur once iron deficiency becomes present in brain tissue. For women with unexplained prolonged fatigue, iron deficiency should be considered when ferritin values are below $50 \mu \mathrm{g} / \mathrm{L}$, even when hemoglobin values are above $12.0 \mathrm{~g} / \mathrm{dL}$. Biological markers can be tested at six weeks to confirm iron deficiency. Recent advances in neuroscience ${ }^{32}$ and imagery ${ }^{33}$ enable iron load to be observed in the central nervous system, which should make it possible to investigate brain iron deficiency independently of iron-deficiency anemia.

\section{Strength and limitations}

Collecting data from a network of general practitioners in private practices provided insight into the feasibility and practical implications of iron supplementation in primary care.

A major limitation of our study was that blinding could not be totally assured because of the side effects of iron supplementation that could differentiate it from a placebo, including stool colour and digestive effects. However, we did not observe any differences in constipation, stomach ache, diarrhea or other digestive events between groups because a low dose of prolonged-release ferrous sulfate was used. We did not ask participants to guess their group assignment because Bruner and colleagues ${ }^{23}$ found no differences between iron and placebo groups when the participants guessed about treatment assignment, despite the use of elemental iron doses that were three times higher than those used in our study. The heterogeneity of responses to treatment for both subjective and objective outcomes makes it very difficult to determine subgroups of responders. Furthermore, imputation methods require data to be missing at random, which we cannot totally assume. Another weakness of our study is that fatigue is a subjective, patient-centred measure; however, using three different measures of fatigue and confirming the results with laboratory surrogates (hemoglobin and ferritin concentrations) increased the internal validity of our results.

\section{Conclusion}

Iron deficiency may be an under-recognized cause of fatigue in women of child-bearing age. If fatigue is not due to secondary causes, the identification of iron deficiency as a potential cause may prevent inappropriate attribution of symptoms to putative emotional causes or life stressors, thereby reducing the unnecessary use of health care resources, including inappropriate pharmacologic treatments.

\section{References}

1. Ridsdale L, Evans A, Jerrett W, et al. Patients with fatigue in general practice: a prospective study. BMJ 1993;307:103-6.

2. Patterson AJ, Brown WJ, Powers JR, et al. Iron deficiency, general health and fatigue: results from the Australian Longitudinal Study on Women's Health. Qual Life Res 2000;9:491-7.

3. Verdon F, Burnand B, Fallab Stubi CL, et al. Iron supplementation for unexplained fatigue in non-anaemic women: double blind randomized placebo controlled trial. BMJ 2003;326:1124-6.

4. Rushton DH, Dover R, Sainsbury AW, et al. Why should women have lower reference limits for haemoglobin and ferritin concentrations than men? BMJ 2001;322:1355-7.

5. Heath AL, Fairweather-Tait S, Worwood M. Reference limits for haemoglobin and ferritin. If it's not broken, don't fix it. BMJ 2001;323:806-7.

6. Becker LA. Oral iron therapy reduced unexplained fatigue in non-anaemic women with serum ferritin concentrations $\leq 50$ $\mu \mathrm{g} / \mathrm{l}$. Evid Based Med 2004;9:47.

7. Godwin M, Ruhland L, Casson I, et al. Pragmatic controlled clinical trials in primary care: the struggle between external and internal validity. BMC Med Res Methodol 2003;3:28.

8. Roland M, Torgerson DJ. What are pragmatic trials? BMJ 1998; 316:285.

9. Pichot P, Brun JP. Brief self-evaluation questionnaire for depressive, asthenic and anxious dimensions. Ann Med Psychol (Paris) 1984;142:862-5

10. Belza BL. Comparison of self-reported fatigue in rheumatoid arthritis and controls. J Rheumatol 1995;22:639-43.

11. Ware J Jr, Kosinski M, Keller SD. A 12-Item Short-Form Health Survey: construction of scales and preliminary tests of reliability and validity. Med Care 1996;34:220-33.

12. Schwartz AL, Meek PM, Nail LM, et al. Measurement of fatigue. determining minimally important clinical differences. $J$ Clin Epidemiol 2002;55:239-44.

13. Krayenbuehl PA, Battegay E, Breymann C, et al. Intravenous iron for the treatment of fatigue in nonanemic, premenopausal women with low serum ferritin concentration. Blood 2011;118: 3222-7.

14. Krafft A, Perewusnyk G, Hanseler E, et al. Effect of postpartum iron supplementation on red cell and iron parameters in nonanaemic iron-deficient women: a randomised placebo-controlled study. BJOG 2005;112:445-50.

15. McClung JP, Karl JP, Cable SJ, et al. Randomized, double-blind, placebo-controlled trial of iron supplementation in female soldiers during military training: effects on iron status, physical performance, and mood. Am J Clin Nutr 2009;90:124-31.

16. Waldvogel S, Pedrazzini B, Vaucher P, et al. Clinical evaluation of iron treatment efficiency among non-anemic but iron-deficient female blood donors: a randomized controlled trial. BMC Med 2012;10:8.

17. Patterson AJ, Brown WJ, Roberts DC. Dietary and supplement treatment of iron deficiency results in improvements in general health and fatigue in Australian women of childbearing age. $J \mathrm{Am}$ Coll Nutr 2001;20:337-42.

18. Brownlie T, Utermohlen V, Hinton PS, et al. Marginal iron deficiency without anemia impairs aerobic adaptation among previously untrained women. Am J Clin Nutr 2002;75:734-42.

19. Brownlie T, Utermohlen V, Hinton PS, et al. Tissue iron deficiency without anemia impairs adaptation in endurance capacity after aer- 
obic training in previously untrained women. Am J Clin Nutr 2004; 79:437-43.

20. Brutsaert TD, Hernandez-Cordero S, Rivera J, et al. Iron supplementation improves progressive fatigue resistance during dynamic knee extensor exercise in iron-depleted, nonanemic women. Am J Clin Nutr 2003;77:441-8.

21. Hinton PS, Giordano C, Brownlie T, et al. Iron supplementation improves endurance after training in iron-depleted, nonanemic women. J Appl Physiol 2000;88:1103-11.

22. Grote L, Leissner L, Hedner J, et al. A randomized, doubleblind, placebo controlled, multi-center study of intravenous iron sucrose and placebo in the treatment of restless legs syndrome. Mov Disord 2009;24:1445-52.

23. Bruner AB, Joffe A, Duggan AK, et al. Randomised study of cognitive effects of iron supplementation in non-anaemic irondeficient adolescent girls. Lancet 1996;348:992-6.

24. Murray-Kolb LE, Beard JL. Iron treatment normalizes cognitive functioning in young women. Am J Clin Nutr 2007;85:778-87.

25. Falkingham M, Abdelhamid A, Curtis P, et al. The effects of ora iron supplementation on cognition in older children and adults: a systematic review and meta-analysis. Nutr J 2010;9:4.

26. Dallman PR. Biochemical basis for the manifestations of iron deficiency. Annu Rev Nutr 1986;6:13-40.

27. Erikson KM, Jones BC, Hess EJ, et al. Iron deficiency decreases dopamine $\mathrm{D}_{1}$ and $\mathrm{D} 2$ receptors in rat brain. Pharmacol Biochem Behav 2001;69:409-18.

28. Yehuda S, Youdim MB. Brain iron: a lesson from animal models. Am J Clin Nutr 1989;50:618-25, discussion 25-9.

29. Beard JL. Iron biology in immune function, muscle metabolism and neuronal functioning. J Nutr 2001;131(2S-2):568S-579S

30. Goodnough LT, Nemeth E, Ganz T. Detection, evaluation, and management of iron-restricted erythropoiesis. Blood 2010;116:4754-61.

31. Rushton DH, Barth JH. What is the evidence for gender differences in ferritin and haemoglobin? Crit Rev Oncol Hematol 2010;73:1-9.

32. Murray-Kolb LE. Iron status and neuropsychological consequences in women of reproductive age: What do we know and where are we headed? J Nutr 2011;141:747S-755S.

33. Duyn JH. High-field MRI of brain iron. Methods Mol Biol 2011; 711:239-49.

Affiliations: From the Department of Community Medicine and Primary Care (Vaucher), University of Geneva, Switzerland; the National College of General Practitioners (Druais),
Le Port Marly, France; the Blood Transfusion Service of the Swiss Red Cross (Waldvogel), Lausanne, Switzerland; and the Department of Ambulatory Care and Community Medicine (Favrat), University of Lausanne, Switzerland.

Contributors: Pierre-Louis Druais conceived the design of the study in collaboration with Pierre Fabre Médicament. Bernard Favrat and Paul Vaucher planned the analysis; reconstructed the entire database for analysis from crude data; verified and crosschecked all data for adverse events, loss to follow-up and deviations from protocol; analyzed results, interpreted data and wrote the manuscript. Sophie Waldvogel interpreted data. All authors revised the manuscript and approved the final version submitted for publication.

Funding: The study was sponsored and funded by Pierre Fabre Médicament; however, the authors worked independently and were financed by their own academic institutions. Pierre Fabre Médicament, Boulogne, France, designed the study and was responsible for collecting and managing data. Pierre Fabre Médicament accorded total independence to Paul Vaucher, Bernard Favrat and Sophie Waldvogel in their analysis, interpretation of data, and preparation and approval of the manuscript. All authors had full access to all data (including intermediate reports, full databases, statistical reports and reports on adverse events) in the study and take responsibility for the integrity of the data and the accuracy of the data analysis. Authors from the universities of Lausanne and Geneva did not receive any financial or material favours from Pierre Fabre for their contributions and were entirely financed by their institutions. Statistical analysis was done by Paul Vaucher; no compensation or funding was received for conducting the analysis.

Acknowledgments: This study is dedicated to Lucienne Avril, who regretfully passed away before this manuscript could be written. She had piloted the entire project on behalf of Pierre Fabre Médicament. We hope that what was achieved will honour her kindness and the rigour of her work. We thank San Francisco Edit for assistance with manuscript preparation. 